\title{
Simulation of the Iberian Electricity Market Using an Agent Based Model and Considering Hydro Stations
}

\author{
José Carlos Sousa \\ FEUP/DEEC and EDP Produção \\ Rua Dr. Roberto Frias, \\ 4200-465 Porto, Portugal \\ jose.sousa@edp.pt
}

\author{
João Tomé Saraiva \\ FEUP/DEEC and INESC TEC \\ Rua Dr. Roberto Frias, \\ 4200-465 Porto, Portugal \\ jsaraiva@fe.up.pt
}

\begin{abstract}
In the last decades power systems witnessed the implementation of an organizational and operational restructuring that lead to the introduction of competitive mechanisms in some activities of the value chain. This is the case of generation and retailing with the development of wholesale and retail markets. These developments together with a renewed emphasis on the adoption of more sustainable solutions while maintaining adequate security of supply levels contributed to increase the interest of generation companies for models enabling the optimization of the use of generation assets or for models and tools to help them to prepare and test bidding strategies to the day-ahead markets. Having in mind the increased complexity of the operation of power systems, AgentBased Models, ABM, are been used to complement the traditional optimization and equilibrium models, taking advantage of the interaction between agents acting in a simulation environment. In this scope, this paper describes an ABM model that uses Q-learning to provide knowledge for the agents to behave in an optimal way. This model is designed to mimic the main features of the common electricity market between Portugal and Spain, the MIBEL. Apart from describing the developed model, this paper also includes preliminary results from its application to the MIBEL case.
\end{abstract}

Index Terms - electricity markets, hydro stations, Agent Based Models, Q-learning.

\section{INTRODUCTION}

In the last thirty years, power systems in several countries were subjected to a deep restructuring process regarding their organizational structure as well as issues related to operation planning activities. These changes were motivated by a variety of reasons that included the adoption of more liberalized models in several economic activities that emerged in the $80^{\text {th }}$ and $90^{\text {th }}$ of last century, the wish to give a stronger role to end consumers, the introduction of new generation technologies (namely renewables and the abundance of natural gas in several locations), the increasing concerns about climate change and the need to increase energy efficiency and technological developments that enabled the adoption of more decentralized and communication demanding solutions.

As a result of these developments the power industry in several countries was subjected to restructuring processes that unbundled the traditional vertically integrated utilities and reorganized the industry in three main activities: generation, wiring (transmission and distribution) and retailing. Typically, wiring transmission and distribution activities are provided by regulated monopolies, and generation and retailing are opened to competition using a variety of contractual and procurement mechanisms that include centralized forward markets (for instance, day ahead markets or financial markets with longer maturity periods) and bilateral contracting.

As a result of these changes and apart from implications in the way that expansion planning activities are now conducted, namely because there is a large number of generation, retailing and end consumers using the networks, the use of generation assets and the related operation planning is now carried out in a very different way when compared with the past. In the scope of day ahead electricity markets, generation companies have to submit selling bids (and also buying bids if pumping hydro stations are available) and these bids have to be carefully prepared and framed by adequate operation strategies so that the revenues are maximized. This is the main reason why the simulation of electricity markets is becoming an area of study for generation companies and for the scientific community namely to forecast their evolution as well as to help market agents to prepare successful bids. Taking into account the evolution of electricity markets and the large number of participating agents, operation planning is thus getting increasingly complex.

In the scope of these changes, Portugal and Spain adopted since the last decade of the XX century very active policies to induce investments in renewable and other endogenous sources. By the end of 2015 wind, solar, biomass and several cogeneration assets reached an installed capacity close to $40 \%$, which poses new challenges to other generation agents as well as for system operation due to the intermittent nature of some of them. Since 2007, Portugal and Spain integrate a common electricity market termed as MIBEL, a common day ahead and intraday markets plus the possibility of establishing bilateral contracts. This common market has an installed capacity close to $140 \mathrm{GW}$, from which about $27 \mathrm{GW}$ are hydro units and 30 GW correspond to wind parks. The strong presence of zero marginal cost technologies poses a huge challenge to more traditional thermal technologies since there are very frequent periods with a zero system marginal price namely in very windy and rainy periods.

For this reason, Iberian generation companies are increasingly aware of the need to prepare adequate operation strategies for their assets so that they can submit adequate selling bids (and buying bids in the case of pumping storage) as a way to maximize their revenues. In this scope, the 
development of market simulation models that reflect in an accurate way the features of the markets, the behavior of the agents and the main characteristics of the involved technologies is certainly extremely important namely if, as in the MIBEL, the share of hydro, wind and solar technologies is large and pumping is also very relevant.

Recently, agent-based models were reported as a complement to equilibrium models when the problem is too complex to be analyzed by traditional approaches. Agentbased models, ABM, are based on a number of autonomous agents organized in a number of classes having some level of intelligence and selecting the most adequate path depending on their interaction in the context of a multi-agent system acting in a simulation environment [1].

The literature already includes several references to ABM models applied to power systems. However, the available models do not adequately consider a number of features that are present in the MIBEL as the large presence of hydro stations and the relevance of pumping as well as the large share of zero marginal cost intermittent technologies that put a new emphasis on the procurement and contracting of reserves [1]. In view of these shortcomings, a preliminary ABM model was described in $[1,2]$ while $[3,4]$ describe short term Hydro Scheduling models in market environment to estimate the revenues of cascades of hydro stations some of them with pumping capacity. In this paper the original model described in $[1,2]$ is enhanced in two ways. It includes four types of hydro plants (run of river stations, storage stations, pumping storage stations and pure pumping stations) and we are using Q-learning to allow the agents to identify the best actions in view of their interactions with other agents and their participation in the MIBEL market platforms.

Having in mind these main ideas and apart from this Introduction, this paper is organized as follows. Section II overviews the Iberian Electricity Market and Section III provides a brief description on existing approaches to deal with the hydro scheduling with particular emphasis on agentbased models. Section IV describes the proposed agent-based model and Section $\mathrm{V}$ details the results obtained so far. Finally, Section VI draws the most relevant conclusions.

\section{OVERVIEW ON THE IBERIAN ELECTRICITY MARKET}

The Portuguese and Spanish power systems went through several changes in the last forty years. In Portugal, the power industry was nationalized in the 1970 s with the creation of a vertically integrated utility. This structure started to change in 1995 when new legislation was passed organizing the sector in terms of a public service and a market driven sector. The Regulatory Agency was also created in 1995 and is responsible for the publication of several codes and for setting the regulated tariffs. With the coexistence of these two sectors, it was expected that generation units and consumers migrated from the public service to the market driven sector but this transition proved to be very slow.

In Spain, the power system was organized in terms of a number of vertically integrated utilities having regional basis. By the end of 1997 a new law was passed that put in place the
Spanish electricity day-ahead market on the 1st of January 1998. Since then, a fast transition of regulated captive clients to the free market was adopted so that full eligibility was achieved in 2003.

In 2001, the Portuguese and the Spanish governments started talks regarding the creation of a common electricity market that would correspond to one of the regional markets advocated by the EU Commission in the path to implement the internal European energy market. After several deferrals, a common trading mechanism termed as MIBEL was set in place on July 1, 2007 as an extension of the already existing Spanish day-ahead market. In the initial operation years the electricity prices in the two areas were different in a large number of hours due to the application of market splitting to solve interconnection congestions. Nowadays, due to the increase of the interconnection capacity and the increasing share of generation in distribution networks, transmission grids are less loaded so that the number of congested hours declined to less than $10 \%$ of the hours in 2015 and 2016 .

The MIBEL includes a common day-ahead market and an intraday market currently organized in 6 sessions to allow agents to refine and adjust their buying or selling positions. Additionally, in both countries there is a large share of hydro plants displaying a considerable variation in their annual and monthly output. In terms of the renewable electricity generation share, both countries were very successful in increasing the amount of renewables. This corresponded to a strategic policy adopted by successive governments to use more intensively endogenous resources as a way to enlarge the energetic independency. By the end of 2014, wind power reached an installed capacity of $5270 \mathrm{MW}$ out of $17827 \mathrm{MW}$ in Portugal (30\%) and of $22854 \mathrm{MW}$ out of $102259 \mathrm{MW}$ in Spain (22\%) with a contribution to supply the demand of $25 \%$ in Portugal and 21\% in Spain. As a whole, in 2015 and 2016 more than $40 \%$ of the demand was supplied by renewable sources (including large hydro units) in both Portugal and Spain. Finally, the two countries successfully implemented a transition period to allow regulated consumers to migrate to the free market. As an illustration, by the end of 2016 more than $75 \%$ of the Portuguese end consumers responsible for more than $85 \%$ of the demand were already in the free market.

\section{LITERATURE REVIEW ON HYDRO SCHEDULING}

\section{A. Hydro Scheduling Optimization}

The definition of optimized strategies to operate generation units has long been a concern for generation companies and for the scientific community as the well-known concepts of unit commitment, generation dispatch and OPF (Optimal Power Flow) illustrate. With the advent of electricity markets and the introduction of competition in the generation activity, the focus is slightly changed since generation companies have to send their bids to the Market Operator. The preparation of these bids is more complex if hydro units are included in the portfolio and if these units have different characteristics as run of river, reservoir or pumping. Scheduling the operation of a number of hydro stations is a complex task addressed for instance in [3, 4] taking into account the installation of units in cascades, the nonlinear 
relation between the head, the power and the flow as well as the pumping capacity of some units. Apart from the iterative procedure adopted in [3] and the genetic algorithm used in [4], other tools have been used to solve the Hydro Scheduling Problem, HSP, as for instance dynamic programming used in [5] (affected by the well-known "curse of dimensionality"), mixed integer linear programming [6] or meta-heuristics, as Simulated Annealing [7] and Neural Networks [8]. Finally, in [9] it is used an iterative approach in which the value of the head and of the market prices are updated along the iterative process in order to model the impact of the operation decisions on the prices and on the revenues, that is, moving from a Price Takers approach to a Price Makers model.

\section{B. Electricity Markets Modeling and ABM}

In recent years, several works were published on electricity market modelling demonstrating the relevance of this topic to the generation companies and researchers. These models can be organized in four main groups as follows [10]:

- Optimization based models usually focused in a single company. These are single firm optimization models designed to maximize the revenues of that company usually considered as price taker;

- Equilibrium Models using Game Theory concepts and considering a larger number of agents and the competition among them;

- Agent-Based Models, ABM, simulating the behavior and the interactions between autonomous agents. This is an interesting alternative when the level of complexity increases turning it difficult to adopt more traditional approaches. Additionally, electricity markets can be represented in a more realistic way and the agents in the simulation environment are designed with some intelligence features that allow them to select the most adequate decisions, the most adequate path in terms of their behavior, in view of the their own objective and the interrelations with other agents;

- Hybrid solutions.

The application of ABM models to power systems and specifically to electricity markets is not new as suggested by $[11,12,13]$. AMES is the acronym for Agent-based Modeling of Electricity Systems and it is an open source to simulate strategic trading behaviors in restructured markets considering AC grids [11]. EMCAS, Electricity Market Complex Adaptive Systems, is a commercial tool developed by the Argone National Lab that includes decentralized agent decisionmaking features along with learning and adaptation capacities. An EMCAS simulation includes both the end users and the demand companies from whom they purchase electricity. EMCAS is linked to VALORAGUA model [12] to provide longer-term operation planning strategies for hydro plants. With this information, EMCAS uses the price forecasts and weekly hydro schedules given by VALORAGUA to provide intra-week hydro plant optimization for hourly supply offers. Finally, MASCEM, Multi Agent based Electricity Market, is a simulation multi-agent platform [13] that includes agents with strategies for bid definition, acting in forward, day-ahead, and balancing markets and considering both simple and complex bids turning it both in a short and a medium term model.
As mentioned in Section I, these tools are not able to adequately model some features of MIBEL as the large share of hydro units, several of them with pumping capacity, together with the large presence of intermittent infra marginal technologies as wind and solar. Therefore, the ABM described in the next Section is designed to represent more accurately hydro units, including pumping, given the flexibility to accommodate large injections from wind parks in some specific periods. Additionally, the model uses Q-learning to provide knowledge to the agents so that they can select the most adequate actions as a way to maximize their revenues.

\section{Developed Agent-Based Model}

\section{A. Agents definition}

ABM models are based on agents organized in classes having different goals according to each of the classes. Once the agents are defined and they are allocated with internal behavioral rules, we adopted a Q-learning procedure to provide them with knowledge to enable them to select the best actions in view of the specified simulation environment.

In this work, we considered the following types of agents: hydro agents organized in four classes depending on the type of hydro unit, thermal power plant agent, renewable unit agent, Market Operator agent, regulated end consumer agent, free consumer agent and Regulatory agent. Hydro agents bid their energy in the day ahead market and their strategy depends on the type of reservoir. The bidding price strategy is determined by the water value on the reservoir, by a learning parameter $\alpha$ and by a decision supporting tool, as described in [2] and modeled by (1). For each hydro unit, the water value function $f$ (water value) provides a reference bid price that changes every day depending on the reservoir level, as illustrated in Figure 1.

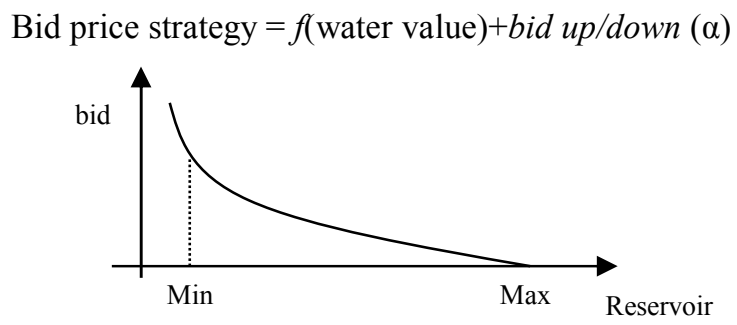

Figure 1. Base bidding taking into account the water value.

This means that if the level is larger, then the value of the stored water is reduced leading to a more reduced biding price. This water value function is an external input to the ABM model and it is calculated for each weak according to the procedure in [2]. In brief words, for each period under analysis the value of the water corresponds to the shadow price of the water balance equation established for that unit and for that period and included in the optimization HSP problem detailed in [3].

The bid up/down $(\alpha)$ parameter models the strategy of each agent by increasing or decreasing its bid price in an attempt to increase the profit. This parameter is set by a learning procedure and it is modeled using a sigmoid function that reflects the risk profile of each agent. If an agent has a 
higher risk profile, the bid range will be larger. Conversely, a low risk profile leads to a narrower bid range as illustrated in the right side of Figure 2. This strategy is an adaptation of the derivative-following strategy discussed in [14] and also used in [13]. A derivative follower does incremental increases (or decreases) in price, continuing to move its price in the same direction until the observed profitability level falls. At this point, the direction of the movement is reversed. This strategy is combined with the Q-learning approach as outlined in [15].
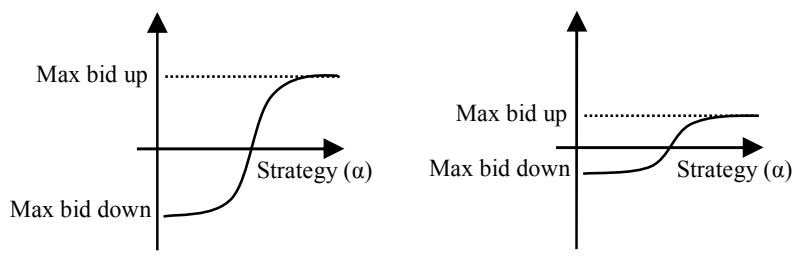

Figure 2. Bidding strategy taking into account the risk profile of each agent.

The developed ABM model organizes the hydro units in four groups having bidding strategies:

- Run of river type - these agents typically have a water value function constant and close to 0 . Since storage capacity is reduced, these units will bid on quantities, that is, the selling bid quantity depends on the inflows;

- Storage type - these agents will have a bid value directed related to their water value function as well as to their bid up/down strategy. This value will depend on their reservoir capability and their inflows;

- Storage with pumping - the bid price is linked to their water value function and a bid up/down strategy. They also have the possibility of buying energy to pump water to their reservoir, taking advantage of low prices;

- Pure pumping - these agents are assigned a zero water value because these are usually small reservoir units. These units adopt an arbitrage bidding strategy that takes advantage of the estimated price difference between peak and off peak periods. Given that the operation decisions will affect the final prices, the energy to buy for pumping purposes is usually limited by a parameter $\beta$. In fact, if energy to pump is increased, then the demand to supply will increase, the market price will also increase and the profit of the unit is decreased. At the end, this turns more risky the operation of these units. The mentioned limiting parameter is updated along the simulation to address this risk and it reflects the relation between the forecasted and the real market prices.

For thermal power plant agents the water value function used by hydro units is substituted by their marginal cost that is dependent on the technology and the fuel. Renewable agents bid at $0 € / \mathrm{MWh}$ in order to ensure their dispatch priority according to the legislation in force in Portugal.

The Market Operator agent is an artifact agent, given that it has not an associated decision making process. It performs the market clearing operations determining the market price and communicating the market results to all market agents.

The developed model incorporates two types of demand agents. Although representing a small amount of the demand, we considered inelastic demand agents to supply regulated consumers. These agents bid at a constant price coinciding to the maximum administrative price admitted in the MIBEL (180 €/MWh). The model also considers elastic demand agents that are designed to buy energy to supply clients that already migrated to the free market, or pumping hydro units. Elastic consumers will be responsible for some demand response regarding price variations in their buying curves.

Finally, the regulatory agent overlooks the generation agents namely checking if bidding prices differ beyond a specified tolerance from the marginal price of thermal stations or the water value for hydro units. If that happens it can impose a penalization to these units or limit the bidding price so that, as the simulation evolves, bid prices more closely follow the typical marginal prices of each technology.

\section{B. $Q$ - Learning methodology}

As mentioned in Section III we introduced in the model the Q-learning procedure detailed in [15]. Q-learning is a reinforcement learning methodology that was originally proposed in [16] and that is fully detailed in [17]. In Qlearning agents can learn an action by interacting with the environment through a trial and error search. This learning approach can be classified as a free model because it doesn't need an explicit knowledge about the environment. Instead, the knowledge regarding the optimal strategy improves while the historic interaction with the environment is being built by a trial and error simulation. Q-learning is a useful algorithm to solve Markov decision based problems, and this is done by evaluating the payoff that can be obtained for a given stateaction pair $\mathrm{Q}(\mathrm{s}, \mathrm{a})$. In [15], and in order to simplify the problem we used 7 states (s1 to s7) as illustrated in Figure 3 to discretize the sigmoid function already described in Fig. 2.

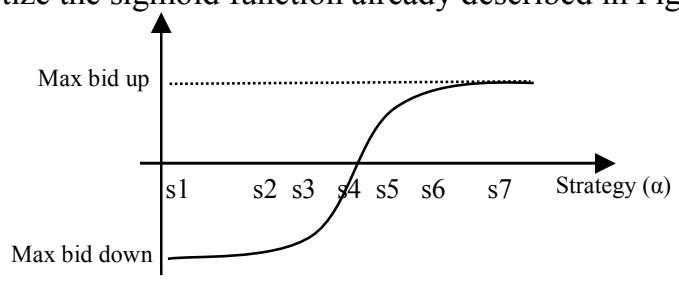

Figure 3. States (s1 to s7) used in Q learning procedure.

State s1 translates a maximum bid down, s4 means that neither a bid up nor a bid down is used and s7 represents a maximum bid up. The actions (a) represent the choice of a different state, as for example a12 is the action associated with the move from $\mathrm{s} 1$ to $\mathrm{s} 2$. The reward or pay off function corresponds to the profit that each agent obtains in the market if an action a is adopted or selected for a given state. So, the Q learning matrix is composed by cells known as $Q$ values for each pair of state (s) and action (a). As the Q learning focuses on the impacts of rewards $(\mathrm{R})$ on the choices of actions in each state, the $Q$ values are obtained by a function that provides the utility that is expected from taking a given action in a given state [16]. The Q(s, a) function is typically given by (2).

$$
\mathrm{Q}(\mathrm{st}, \mathrm{at})=(1-\lambda) \mathrm{Q}(\mathrm{st}, \mathrm{at})+\lambda[\mathrm{R}(\mathrm{st}, \mathrm{at})+\gamma \max \mathrm{Q}(\mathrm{st}+1, \mathrm{at})]
$$

In (2) $\lambda \in(0,1)$ is the learning rate, which controls the degree to which recently learned information will override 
the old one ( $\lambda$ equal to 0 makes the agent not learn, while equal to 1 induces the agent to consider only the most recent information). The parameter $\gamma$ is the discount factor that determines the importance of future reinforcements ( $\gamma$ equal to 0 makes the agent myopic by only considering current rewards, while values closer to 1 turn distant rewards more important). The expression $\max \mathrm{Q}(\mathrm{st}+1$,at) represents the best the agent thinks it can do in state $\mathrm{st}+1$ [16]. In an initial phase, the agents will randomly explore state to state until they reach the end of simulation period. In this case, the simulation ends and the learning process converges when the $\mathrm{Q}$ values do not change more than 5\% regarding the values in the $\mathrm{Q}$ matrix in the previous iteration. Then, using these $Q$ values, the agents start their biddings taking into account the learned experience. This algorithm is detailed in [15] and the parameters used in this study are similar to the ones used in [15].

In [15] we used a single set of states and actions. In this work, we enriched the model introducing 3 different sets of Qvalues according to the monthly inflows. This means that in a dry month an agent will use a $Q$ matrix built for smaller inflows and that will be different from the $\mathrm{Q}$ matrices that were learned for average and for wet inflow months. Accordingly, each agent will learn in a different way taking into account the hydro inflows. This procedure is similar as the one used in [18] applied to the Brazilian power system.

\section{CASE STUdY}

\section{A. Data and Main Assumptions}

In this paper, we used a Case Study closely based in the MIBEL market for 2015. The data regarding the generation systems was obtained in the web pages of the Portuguese and Spanish System Operators (www.ren.pt and www.ree.es). The Portuguese hydro and thermal units and the Spanish thermal units were individually considered. Regarding the Spanish hydro system, the available information is related to 7 cascades. In order to represent more realistic these hydro units, these cascades were divided in blocks of $200 \mathrm{MW}$, and we additionally admitted that $50 \%$ of the installed capacity is associated to run-of-river units and the remaining to larger reservoir units. Regarding the generation from wind parks, PV units, biomass and small hydro units, we admitted that they are included in the market aggregated selling curve at 0 $€ / \mathrm{MWh}$ in both countries as a way to give them priority in the dispatch. The Spanish nuclear power plants were also considered with $0 € / \mathrm{MWh}$ marginal cost. Table I details the generation mix in both countries by the end of 2015 .

TABLE 1. TOTAL CAPACITY AND NUMBER OF POWER PLANTS.

\begin{tabular}{|c|c|c|c|c|}
\cline { 2 - 5 } \multicolumn{1}{c|}{} & \multicolumn{2}{c|}{ Portugal } & \multicolumn{2}{c|}{ Spain } \\
\hline Technology & $\begin{array}{c}\text { Total } \\
\text { Capacity } \\
\text { (MW) }\end{array}$ & $\begin{array}{c}\text { Number } \\
\text { Power } \\
\text { Plants }\end{array}$ & $\begin{array}{c}\text { Total } \\
\text { Capacity } \\
\text { (MW) }\end{array}$ & $\begin{array}{c}\text { Number } \\
\text { Power } \\
\text { Plants }\end{array}$ \\
\hline Hydro storage & 1480 & 13 & 7502 & 35 \\
\hline Hydro pumping & 1215 & 5 & 5350 & 24 \\
\hline $\begin{array}{c}\text { Hydro run of } \\
\text { river }\end{array}$ & 2489 & 14 & 7500 & 35 \\
\hline CCGT & 3847 & 4 & 24948 & 28 \\
\hline Coal & 1756 & 2 & 10468 & 17 \\
\hline Nuclear & 0 & 0 & 7573 & 8 \\
\hline
\end{tabular}

\section{B. Hydro Charaterization}

The inflows of the Spanish hydro units were obtained for each month, in energy for each of the 7 cascades and divided in the same way as the installed capacity. For Portugal, we used hydro inflows for each hydro since they were available on the web page of the Portuguese TSO. The water value function described in Section IV.A for all the hydro reservoirs correspond to the average of the ones obtained in [3]. The global efficiency for the turbine/pumping process was set at 0.8 for all pumping hydro meaning that for $1 \mathrm{MWh}$ of pumping it generates $0.8 \mathrm{MWh}$. In order to be profitable, this means that pumping is activated only if there is at least a relation of 1.25 between the peak/off peak prices. Finally, runoff river units bid at 0 and pure pumping storage was not considered since there are units like this in the Iberian system.

\section{Thermal Charaterization}

The marginal costs of thermal units were obtained using international indexes for 2015 for each technology. For coal we used API2, for natural gas the marginal cost was calculated as an average from Zeebrugge, NBP and the price at the Henry hub and for $\mathrm{CO} 2$ we used the values from Bluenext. To have some differentiation between the different thermal units, we used a degradation factor in the cost calculation that increases the operation cost by $0.5 \%$ per year after commissioning. Using this reasoning, the marginal costs varies from 27 to 31 $€ / \mathrm{MWh}$ for coal and from 50 to $55 € / \mathrm{MWh}$ for CCGT.

\section{Demand and renewble generation}

The demand was based on the real hourly pattern for Portugal and Spain publicly available for 2015. We admitted that this demand is inelastic and for market purposes we admitted that it is prepared to pay the maximum price used in the MIBEL (180 €/MWh). Although a small part of the end user demand has some elasticity, it happens that the demand curve is in reality very close to a vertical line, which means that this assumption translate the real behavior in a close way.

Differently from end users, pumping storage units are modeled as elastic consumers that can eventually adopt a strategy of buying electricity to pump according to the characterization of the agents provided in Section IV.A.

\section{E. Interconnetcion}

The interconnection limit between Portugal and Spain was not considered meaning that Portugal and Spain are a taken as single market. This assumption is close to reality since in 2015 and 2016 congestion occurred in less than $10 \%$ of the hours of these years, that is, market splitting was rarely used and there was in fact a common price in more than $90 \%$ of the hours.

\section{F. Results}

As mentioned, the developed ABM model was applied to the MIBEL electricity market considering hourly data for 2015. The simulations were conducted modelling hydro units as described in Section IV.A, that is, having to decide what is the best bidding strategy, and then not considering this capacity to select a strategy, which means admitting that hydro units bid at $0 € / \mathrm{MWh}$. Table II presents the results for annual average prices that were observed in reality and the values 
obtained with the developed model considering and not considering the hydro bidding strategies. Figure 4 shows the average prices on a weekly basis.

TABLE II. TOTAL CAPACITY AND NUMBER OF POWER PLANTS.

\begin{tabular}{|c|c|}
\hline Scenario & $\begin{array}{c}\text { Annual average MIBEL } \\
\text { Price (€/MWh) }\end{array}$ \\
\hline Real 2015 data & 50.43 \\
\hline Simulation with hydro strategies & 42.72 \\
\hline Simulation with no hydro strategies & 35.01 \\
\hline
\end{tabular}

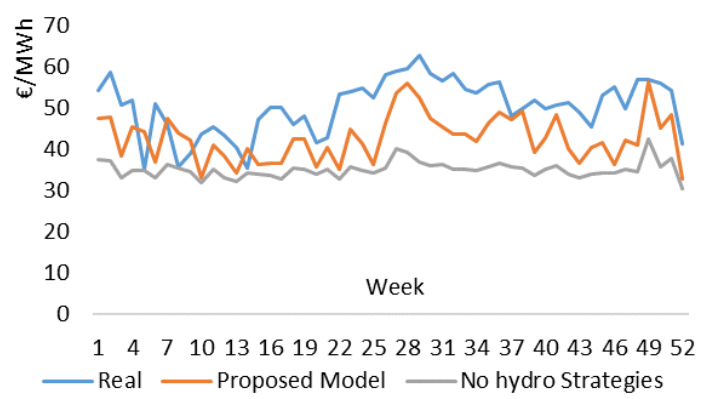

Figure 4. Average weekly results for market prices.

These results show that allowing hydro units to define bidding strategies enable the prices to be much closer to real ones. This improvement is due to the fact that we are using the water value function as well as the bid-up/bid-down and the Q-learning approach. Additionally, Figure 4 suggests that the prices obtained with the developed ABM model are in general below the real ones, although the trend is similar when comparing the blue and the red curves. This difference of prices suggests the presence of an offset affecting the results of the developed model eventually related to the fact that startup and shut-down costs of thermal units were not included and also because the variable costs of thermal units were calculated in a simplified way, namely for the Spanish units. This can be relevant since the Spanish generation system is almost 5 times larger than the Portuguese one, meaning that these simplifications can have a large impact on the results.

\section{CONCLUSIONS}

This paper presents the results obtained with an ABM model to simulate the MIBEL electricity market in 2015 focusing on hydro units and including a Q learning strategy. The results confirm that the agents have learning capabilities and are maximizing their profit using the proposed model. There are still some issues to be enhanced namely related with a more accurate modelling of the variable costs of thermal units. However, this is one of the major difficulties because it is difficult to access real values of these costs. On the other hand, it is important to have an accurate model for hydro units because in the MIBEL these units frequently behave as price makers and their installed capacity is significant so that they really influence the market price. Despite these difficulties, the developed Agent Based model proved that it can be used as a valuable simulation tool namely for complex systems as compared with other traditional optimization models.

\section{ACKNOWLEDGEMNT}

This work is financed by the ERDF - European Regional Development Fund through the Operational Programme for
Competitiveness and Internationalisation - COMPETE 2020 within project «POCI-01-0145-FEDER-006961», and by National Funds through FCT - Fundação para a Ciência e a Tecnologia (Portuguese Foundation for Science and Technology) as part of project UID/EEA/50014/2013.

\section{REFERENCES}

[1] J. C. Sousa, Z. Kokkinogenis, R. Rossetti, J. T. Saraiva, "Electricity Market Modeling and Renewable Energy Integration: an Agent-Based Conceptual Model", in Proc.10th Int. Multidisciplinary Modeling \& Simulation Multiconference, I3M/SESDE 2013, Athens, Sept. 2013.

[2] J. C. Sousa, J. T. Saraiva, Z. Kokkinogenis, R. Rossetti, "Operation Planning of Hydro Power Plants Using Agent Based Models", in Proc. of MedPower 2014, Athens, Nov. 2014.

[3] J. C. Sousa, V. T. Mendes, J. T. Saraiva, "Estimation of the Remuneration of Hydro Plants in a Market Environment Using an Iterative Under-Relaxation Approach", in Proc. 2009 IEEE Bucharest Power Tech, Romenia, 28 June - 2 July 2009.

[4] Guerreiro, C.A., J. T. Saraiva, J. C. Sousa, V. T. Mendes, "Operation planning of hydro stations using genetic algorithms considering their impact on the electricity market prices", in Proc. $11^{\text {th }}$ International European Electricity Market Conference, EEM'14, Kracow, May 2014.

[5] S.-C. Chang, C.-H. Chen, I.-K. Fong, P. B. Luh, "Hydroelectric Generation Scheduling With An Effective Differential Dynamic Programming Algorithm", IEEE Transactions on Power Systems, vol. 5, no. 3, pp. 737-743, August 1990.

[6] G. W. Wang, C. T. Su, "A Practical Mixed Integer Linear Programming Based Short Term Hydro Scheduling", in Proc. of the IEEE Asia-Pacific Trans. and Dist. Conference, vol. 3, pp. 1606-1610, October 2002.

[7] K. Wong, Y. Wong, "A Parallel Simulated Annealing Algorithm for Short-Term Hydro Scheduling", in Proc. $2^{\text {nd }}$ IEEE International Forum on Applications of Neural Networks Power Systems, pp. 335-340, Yokohama, Japan, April 1993.

[8] R. H. Liang, Y. Y. Hsu, "Short-Term Hydro-Scheduling using Hopfield Neural Network", IEE Proc. Generation, Transmission \& Distribution, vol. 143, no. 3, pp. 269-275, May 1996.

[9] M. S. Castro, J. T. Saraiva, J. C. Sousa, "Application of the Matlab Linprog Function to Plan the Operation of Hydro Stations Considered as Price Makers", in Proc. $13^{\text {th }}$ International European Electricity Market Conference, EEM'16, Porto, Portugal, June 2016.

[10]G. Li, J. Shi, X. Qu, "Modeling methods for GenCo bidding strategy optimization in the liberalized electricity spot market-A state-of-the-art review", Energy, vol. 36, no. 8, pp. 4686-4700, August 2011.

[11]H. Li, L. Tesfatsion, "Development of open source software for power market research: The AMES test bed", Journal of Energy Markets, vol. 2, no. 2, pp. 111-128, 2009.

[12]P. Thimmapuram, T. D. Veselka, V. Koritarov, S. Vilela, R. Pereira, R. F. Silva, "Modeling hydro power plants in deregulated electricity markets: Integration and application of EMCAS and VALORAGUA", in Proc. EEM2008, pp. 1-6, May 2008.

[13]Z. Vale, T. Pinto, I. Praça, H. Morais, "MASCEM: electricity markets simulation with strategic agents", IEEE Transactions on Intelligent Systems, vol. 26, no. 2, pp. 9-17, March-April 2011.

[14]A. Greenwald, J. Kephart, and G. Tesauro, "Strategic Pricebot Dynamics", in Proceedings of the $1^{\text {st }}$ ACM Conf. Electronic Commerce, ACM Press, pp. 58-67, Denver, Colorado, Nov. 1999.

[15] J. C. Sousa, J. T. Saraiva, "Simulation of the Operation of Hydro Plants in an Electricity Market Using Agent Based Models - introducing a Q Learning approach", in Proc. $13^{\text {th }}$ International European Electricity Market Conference, EEM'16, Porto, Portugal, June 2016.

[16]C. Watkins, P. Dayan, P. Technical Note: Q-Learning, Machine Learning, vol. 8, pp- 279-292, 1992.

[17] R. S. Sutton, A. G. Barto, Reinforcement Learning: An Introduction. Cambridge, MA, MIT Press, 1998.

[18] F. Calabria, J. T. Saraiva, A. P. Rocha, "A Virtual Reservoir Electricity Market Design Applied to the Brazilian System Using an Agent Based Model", in Proc. $12^{\text {th }}$ International European Electricity Market Conference, EEM'15, Lisbon, Portugal, May 2015. 